NASA Technical Memorandum 107308

\title{
Low Temperature Characterization of Ceramic and Film Power Capacitors
}

\author{
Ahmad Hammoud \\ NYMA, Inc. \\ Brook Park, Ohio \\ and \\ Eric Overton \\ Lewis Research Center \\ Cleveland, Ohio
}

Prepared for the 1996 Conference on Electrical Insulation and Dielectric Phenomena sponsored by the IEEE Dielectrics and Electrical Insulation Society Millbrae, California, October 20-23, 1996

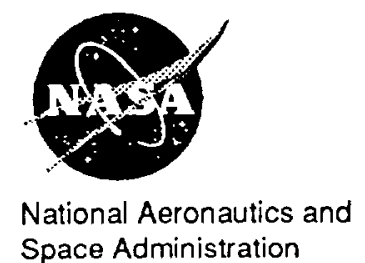

Space Administration 



\title{
Low Temperature Characterization of Ceramic and Film Power Capacitors
}

\author{
Ahmad Hammoud \\ NYMA, Inc. \\ NASA Lewis Research Group \\ Cleveland, Ohio 44135 \\ Eric Overton \\ NASA Lewis Research Center \\ Cleveland, Ohio 44135
}

\begin{abstract}
Among the key requirements for advanced electronic systems is the ability to withstand harsh environments while maintaining reliable and efficient operation. Exposures to low temperature as well as high temperature constitute such stresses. Applications where low temperatures are encountered include deep space missions, medical imaging equipment, and cryogenic instrumentation. Efforts were taken to design and develop power capacitors capable of wide temperature operation. In this work, ceramic and film power capacitors were developed and characterized as a function of temperature from $20{ }^{\circ} \mathrm{C}$ to $-185^{\circ} \mathrm{C}$ in terms of their dielectric properties. These properties included capacitance stability and dielectric loss in the frequency range of $50 \mathrm{~Hz}$ to $100 \mathrm{kHz}$. DC leakage current measurements were also performed on the capacitors. The manuscript presents the results that indicate good operational characteristic behavior and stability of the components tested at low temperatures.
\end{abstract}

\section{Introduction}

Future power systems emphasize compactness, lightweight, reliability and highly efficient operation. In addition, exposure of the power system to temperature excursions during their lifetimes is anticipated in a wide span typical of space missions and certain terrestrial applications. Included are deep space exploration, communication satellites, cryogenic instrumentation, superconducting magnetic energy storage systems, and magnetic levitation transportation systems [1]. For example, electronic instrumentation and power systems deployed near Pluto will encounter temperatures as low as $-229^{\circ} \mathrm{C}$ [2]. The development of electrical components and systems capable of extreme temperature operation represents, therefore, a key element to meeting the technological challenges and to fulfilling the requirements of advanced space power systems. In addition, the operation of advanced space power electronics at low temperature will result in higher efficiency and lower cost (due to reduced active thermal management) [3].

Commercially available power components are limited in their temperature handling capability due to limitations in the materials being used (semiconductor, dielectrics and magnetics), or due to the current design practices, processing and manufacturing techniques (metallization, packaging and encapsulation). Identification of new materials and components capable of providing reliable and efficient operation at low temperatures, and improvement in design topologies and processing techniques thus play an important role for the development of advanced space and other electrical power systems.

Research efforts to develop lightweight, reliable wide temperature power inverters for space-based applications are being performed at the NASA Lewis Research Center [4]. Efforts have been made to design and develop power capacitors capable of wide temperature operation. In this work, ceramic and film power capacitors were developed and characterized as a function of temperature from $20^{\circ} \mathrm{C}$ to $-185^{\circ} \mathrm{C}$ in terms of their dielectric properties. These properties included capacitance stability and dielectric loss in the 
frequency range of $50 \mathrm{~Hz}$ to $100 \mathrm{kHz}$. DC leakage current measurements were also performed on the capacitors. The results that indicate good operational behavior and stability of the components tested at low temperatures are presented and discussed in this paper.

\section{Experimental Procedures}

In previous studies, at NASA Lewis Research Center, power capacitors made of ceramic COG/NPO (Olean Advanced Products), 3M polymer film (Northrop Grumman STC) as well as metallized-teflon film (Component Research Company) were evaluated at high temperatures. These experiments were carried out to evaluate the effects of temperature on the stability of the various electrical properties of the capacitors. They were characterized at temperatures ranging from room temperature to $200^{\circ} \mathrm{C}$. Then, subsequent experiments evaluated the effects of short-term (12 weeks) and longterm (35 weeks) thermal aging on the electrical properties of the capacitors. In the long-term aging tests, the effects of simultaneous thermal aging and electrical stressing on the electrical properties of the ceramic and film capacitors were examined [5].

Of the ceramic COG/NPO and $3 \mathrm{M}$ film types, three power capacitors each were selected for low temperature evaluation. The number of candidates selected was restricted by availability and cost and based upon previous experimentation. This sample size is quite sufficient for these types of tests. Table I. ..sts some of the design requirements and manufacturers specifications $[6,7]$.

The capacitors were prepared by soldering connectors onto the leads using a $\mathrm{Sn}_{95} \mathrm{Ag}_{s}$ type solder. The conductors used to make the connections from the components to the instrumentation had insulation made of teflon, which is capable of withstanding low temperatures without experiencing structural damages. After the necessary preparations and connections were completed, the components were then placed in a Sun Systems Model EClx Environmental Chamber. This chamber is capable of reaching temperatures ranging from approximately $-185^{\circ} \mathrm{C}$ (using refrigerated liquid nitrogen) to $300^{\circ} \mathrm{C}$.

Capacitance, dissipation factor, and DC leakage current values were obtained at room temperature as a reference. A GenRad Model 1689 Precision RLC Digibridge was used to make the capacitance and dissipation factor measurements at various frequencies ranging from $50 \mathrm{~Hz}$ to $100 \mathrm{kHz}$. This computer programmable digibridge was used in an automated mode using a computer. A Keithley Model 237 Source Measurement Unit was used to make the DC leakage current measurements. After the initial room temperature measurements were made, subsequent measurements were made at 25 degree increments down to $-185^{\circ} \mathrm{C}$. The components were allowed to soak at the various test temperatures for a period of 30 minutes before any measurements were made. Leakage currents were recorded after an electrification time of 5 minutes in accordance with the ASTM standards. This designated electrification allows the capacitors to charge and the leakage current to stabilize. After each leakage current measurement was made, the capacitors were discharged.

\section{Results}

Three capacitors of each type were subjected to characterization. All capacitors of the same type displayed similar behavior upon testing and showed good reproducibility. Therefore, the data presented and discussed in this paper was obtained for one capacitor of each type. This data was represented of all the units tested of the same type.

Figure 1 shows the change in capacitance with temperature at $50 \mathrm{~Hz}$ for both the ceramic and the film capacitors. It can be clearly seen that while the ceramic capacitor displayed excellent stability with temperature, the film capacitor exhibited a decreasing capacitance with decreasing temperature. At a test temperature of $-185^{\circ} \mathrm{C}$ for example, the capacitance of the film capacitor dropped about $7 \%$ compared to its room temperature value. Similar trends were observed for both types of the capacitors at all test frequencies from $50 \mathrm{~Hz}$ to $100 \mathrm{kHz}$. The data in Figure 2, which was obtained at a test frequency of $20 \mathrm{kHz}$, indicate the similarity in the behavior of the capacitance stability and its independence of the test frequency.

Figure 3 shows the dissipation factor of the ceramic and the film capacitors as a function of temperature at 50 $\mathrm{Hz}$, and Figure 4 shows the data for $20 \mathrm{kHz}$. At all frequencies, the ceramic capacitors exhibited stability in its dissipation factor with temperature. The dissipation factor of the film capacitor, however, started to increase initially with decreasing temperature until it reached a peak, after which it started to decrease with further decrease in temperature. These peaks occurred at $-75^{\circ} \mathrm{C}$ and $-25^{\circ} \mathrm{C}$ at the test frequencies of $50 \mathrm{~Hz}$ 
and $20 \mathrm{kHz}$, respectively. It is interesting to note that in the very low temperature regime and at all frequencies, the dissipation factor of the film capacitor attained a value lower than its room temperature value.

Figure 5 depicts the leakage current of the capacitors as a function of temperature. It can be seen that opposite trends occurred in this property of the two capacitors with varying temperature. The leakage current of the ceramic capacitor decreased with decreasing test temperature. The leakage current of the film capacitor first increased as the test temperature was lowered, reaching a peak at around $-150{ }^{\circ} \mathrm{C}$, and then it decreased to recover to its room temperature value as the temperature was further decreased. Similar behavior was observed in the dissipation factor property of these film capacitors as seen above.

The changes in the dielectric properties of the film capacitors with temperature can be attributed to many factors. These include morphology of the polymer film, dipole orientation, ionic impurities, molecular agitation, and electronic polarization.

\section{Conclusions}

The results obtained in this work indicate that the dielectric properties depend greatly on the temperature. Amongst the capacitors tested, the ceramic capacitor has shown superiority in terms of thermal stability. Further experimental studies are required to better and fully characterize these and other capacitors for potential use in low or wide temperature environments.

\section{Acknowledgements}

This work was supported, in part, by NASA Lewis Research Center, Contract \# 27186, Task Order \#543004.

\section{References}

[1]. B. Ray, S. S. Gerber, R. L. Patterson, and I. T. Myers, "Liquid Nitrogen Temperature Operation of a Switching Power Converter", Low Temperature Electronics and High Temperature Superconductivity Symposium, Reno, Nevada, May 21-26, 1995.
[2]. B. Ray and R. L. Patterson, "Wide Temperature Operation of a PWM DC-DC Converter", IEEE Industry Applications Society Conference, Orlando, Florida, October 8-12, 1995.

[3]. R. K. Kirschman, "Low Temperature Electronics Device Operation," The Electromechanical Society, PV 91-14, 1991.

[4]. A. N. Hammoud, E. D. Baumann, I. T. Myers, and E. Overton, "High Temperature Power Electronics for Space", First International High Temperature Electronics Conference, Albuquerque, New Mexico, June 16-20, 1991.

[5]. E. Overton, A. N. Hammoud, E. D. Baumann, and I. T. Myers, "Effects of Combined Stressing on the Electrical Properties of Film and Ceramic Capacitors", IEEE International Symposium on Electrical Insulation, Pittsburgh, Pennsylvania, June 58, 1994.

[6]. Olean Advanced Products, Chip Capacitors No. AOL-0959-01.

[7]. E. F. Hampl, Jr., $3 \mathrm{M}$ Company presentation, January, 1990. 


\begin{tabular}{|c|c|c|}
\hline Property & Film & Ceramic \\
\hline \hline Capacitance $(\mu \mathrm{F})$ & 1.0 & 1.0 \\
\hline $\begin{array}{c}\text { Capacitance Tolerance } \\
(\%)\end{array}$ & 5 & \pm 10 \\
\hline $\begin{array}{c}\text { Voltage (VDC) } \\
\text { Temperature }\left({ }^{\circ} \mathrm{C}\right)\end{array}$ & $-6510+200$ & -55 to +200 \\
\hline $\begin{array}{c}\text { Normal Operating } \\
\text { Dissipation Factor }(\%)\end{array}$ & $0.05 \mathrm{Max} @ 25^{\circ} \mathrm{C}$ & $0.15 \mathrm{Max} @ 25^{\circ} \mathrm{C}$ \\
\hline
\end{tabular}

Table I. Capacitors Specifications.

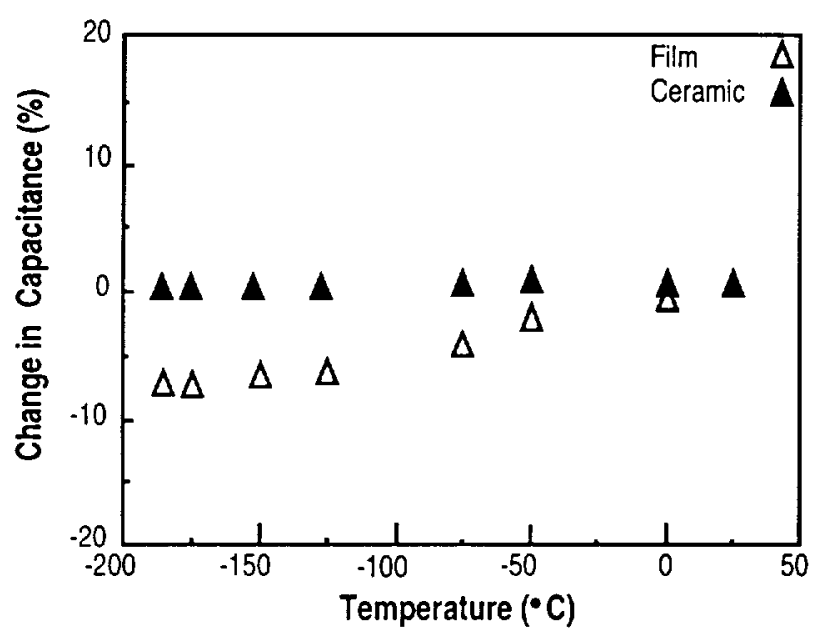

Figure 1. Capacitance of film and ceramic capacitors at $50 \mathrm{~Hz}$ versus temperature.

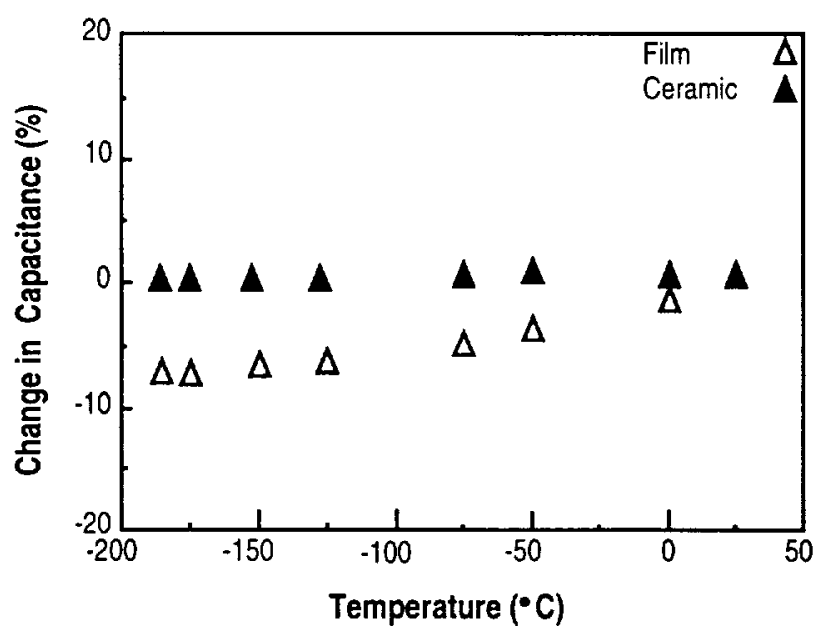

Figure 2. Capacitance of film and ceramic capacitors at $20 \mathrm{kHz}$ versus temperature.

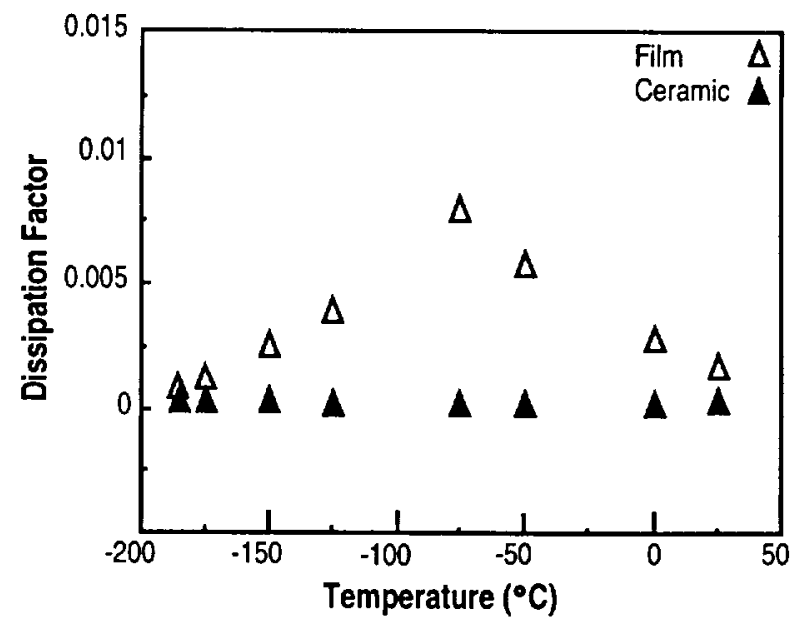

Figure 3. Dissipation factor of film and ceramic capacitors at $50 \mathrm{~Hz}$ versus temperature.

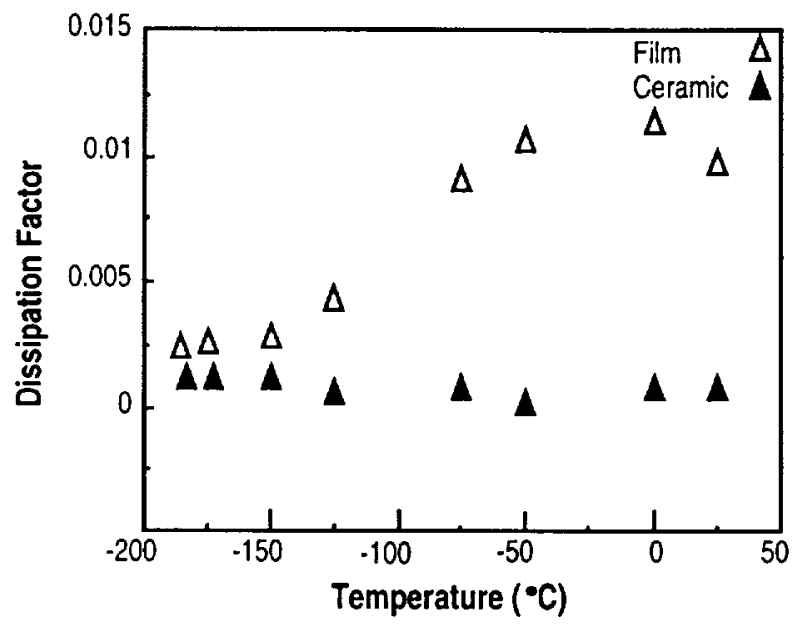

Figure 4. Dissipation factor of film and ceramic capacitors at $20 \mathrm{kHz}$ versus temperature.

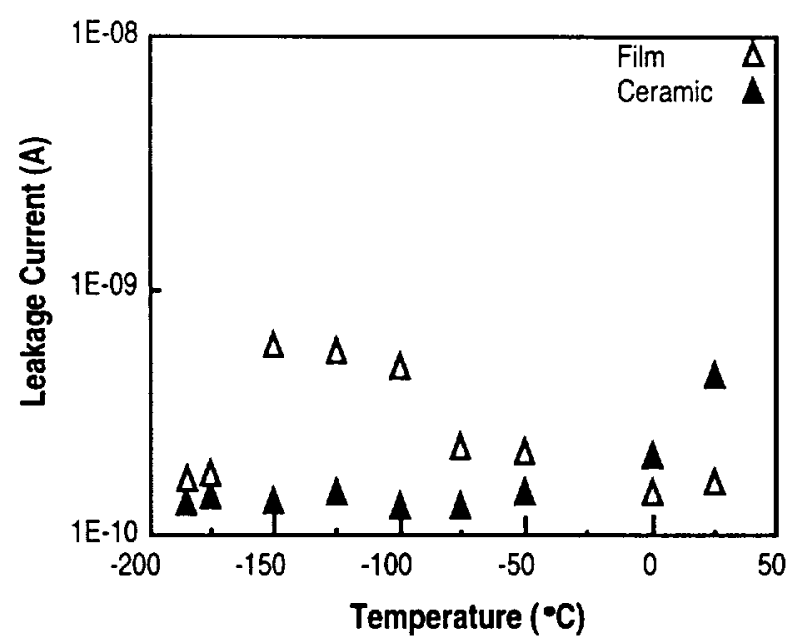

Figure 5. Leakage current of film and ceramic capacitors as a function of temperature. 


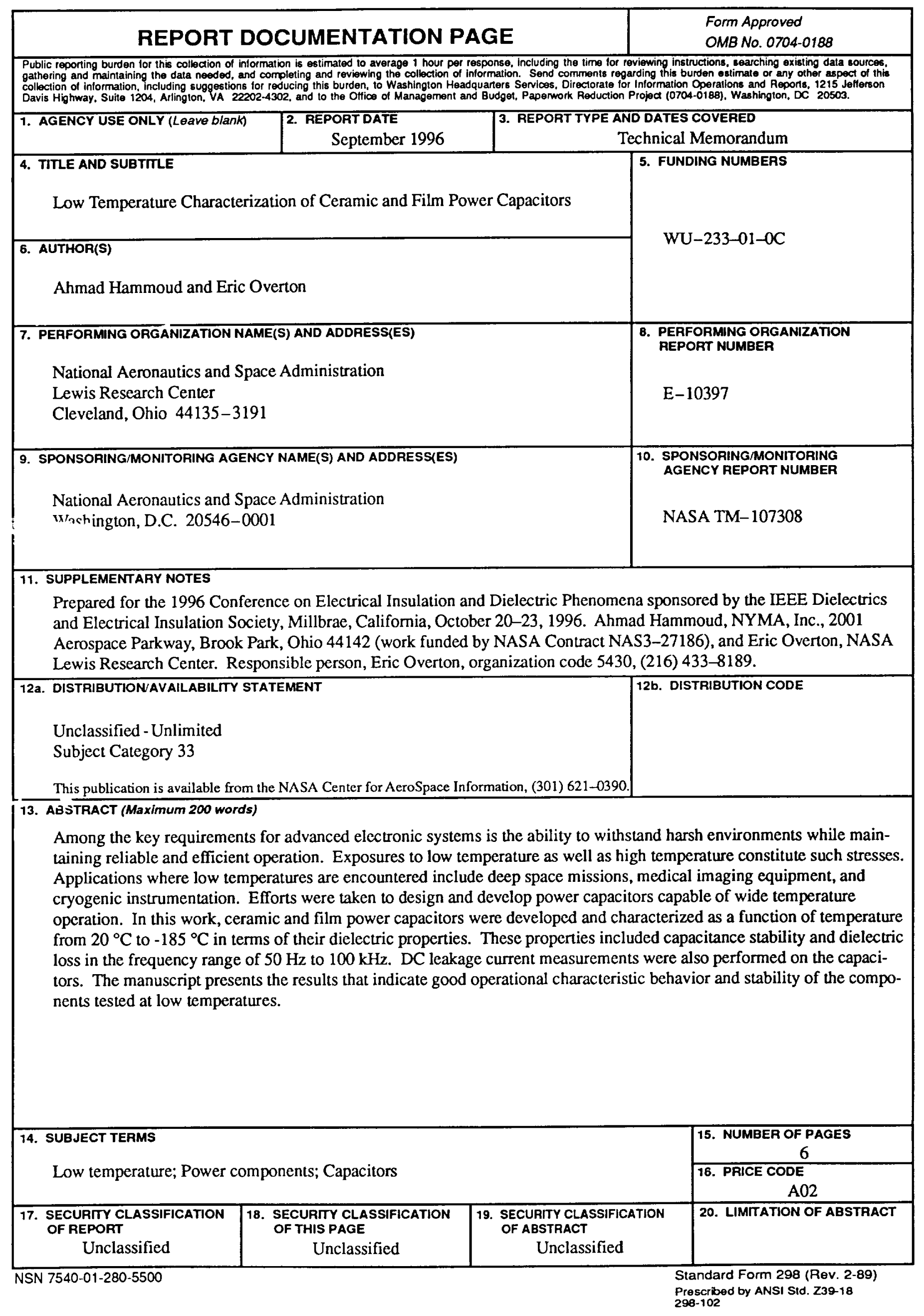




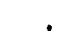




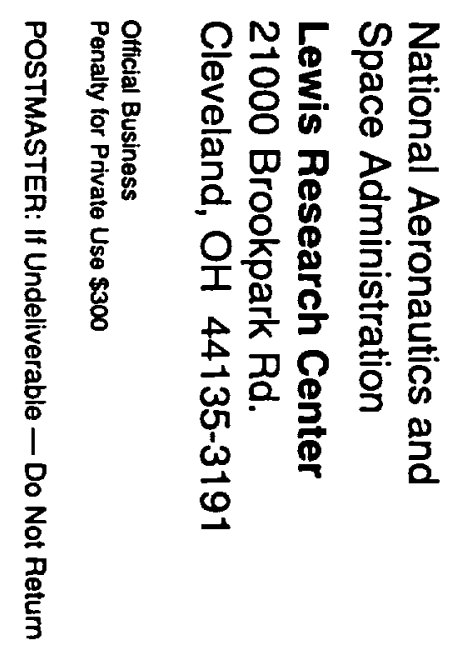

